\title{
Vertical Variation of $Z-R$ Relationship at Hallasan Mountain during Typhoon Nakri in 2014
}

\author{
Chulsang Yoo ${ }^{1}$ and Jung Mo $\mathrm{Ku}^{2}$ \\ ${ }^{1}$ School of Civil, Environmental and Architectural Engineering, College of Engineering, Korea University, \\ Seoul 136-705, Republic of Korea \\ ${ }^{2}$ Department of Civil, Environmental and Architectural Engineering, College of Engineering, Korea University, \\ Seoul 136-713, Republic of Korea \\ Correspondence should be addressed to Jung Mo Ku; kjm1868@nate.com
}

Received 19 January 2017; Revised 4 April 2017; Accepted 26 April 2017; Published 30 May 2017

Academic Editor: Roberto Fraile

Copyright (C) 2017 Chulsang Yoo and Jung Mo Ku. This is an open access article distributed under the Creative Commons Attribution License, which permits unrestricted use, distribution, and reproduction in any medium, provided the original work is properly cited.

\begin{abstract}
Hallasan Mountain is located at the center of Jeju Island, Korea. Even though the height of the mountain is just 1,950 m, the orographic effect is strong enough to cause heavy rainfall. In this study, a rainfall event, due to Typhoon Nakri in 2014, observed in Jeju Island was analyzed fully using the radar and rain gauge data. First, the $Z-R$ relationship $\left(Z=A R^{b}\right)$ was derived for every $250 \mathrm{~m}$ interval from the sea level to the mountain top. The resulting $Z-R$ relationships showed that the exponent $b$ could be assumed as constant but that the parameter $A$ showed a significant decreasing trend up to an altitude around $1,000 \mathrm{~m}$ before it increased again. The orographic effect was found to be most significant at this altitude of $1,000 \mathrm{~m}$. Second, the derived $Z$ - $R$ relationships were applied to the corresponding altitude radar reflectivity data to generate the rain rate field over Jeju Island. This rain rate field was then used to derive the areal-average rain rate data. These data were found to be very similar to the rain gauge estimates but were significantly different from those derived from the application of the Marshall-Palmer equation to the $1.5 \mathrm{~km}$ CAPPI data, which is the data type that is generally used by the Korea Meteorological Administration (KMA).
\end{abstract}

\section{Introduction}

The rain rate in a mountain area is generally higher than that in a flatland, which is mostly caused by the ascending air current, called the orographic effect [1-6]. Hallasan Mountain in Jeju Island, Korea, is also famous for heavy rainfall. With its height of 1,950 m, the heavy rainfall at Hallasan Mountain is believed to be due to the orographic effect [7]. The rainfall amount in the mountain area is more than twice that in the coastal area [8]. It was also shown that the rainfall amount is linearly increased at Hallasan Mountain proportional to the altitude [9]. A similar result was also derived by Choi [10], whereby an analysis of the rain rate data over the 10 years from 2003 to 2012 shows that the annual rainfall amount in Jeju Island is generally proportional to the altitude.

However, in general, it is not easy to capture the orographic effect. It is mainly because the number of rain gauges available in a mountain area is very limited. Similar situation is also found in Jeju Island. A total of 24 rain gauges are being operated in Jeju Island, of which just four are located in the mountain area with altitudes of $600 \mathrm{~m}$ or higher [8]. The reported orographic effect at Hallasan Mountain [8] is just the comparison of rainfall data measured at the coastal area and in the mountain area. Such systematic behavior or change of rainfall from the coastal area to the mountain area could not be derived because of the limit of available information from rain gauges.

In that sense, the radar can be a good tool to provide valuable information about the rainfall in a mountain area. Fortunately, two radars are being operated in Jeju Island. These were introduced mainly to monitor the typhoons that approach the Korean Peninsula [11]. In fact, two radars were introduced as Hallasan Mountain causes the severe beam blockage. As these two radars cover the entirety of Hallasan Mountain, they can provide valuable information for an analysis of the rain rate field over the mountain. 


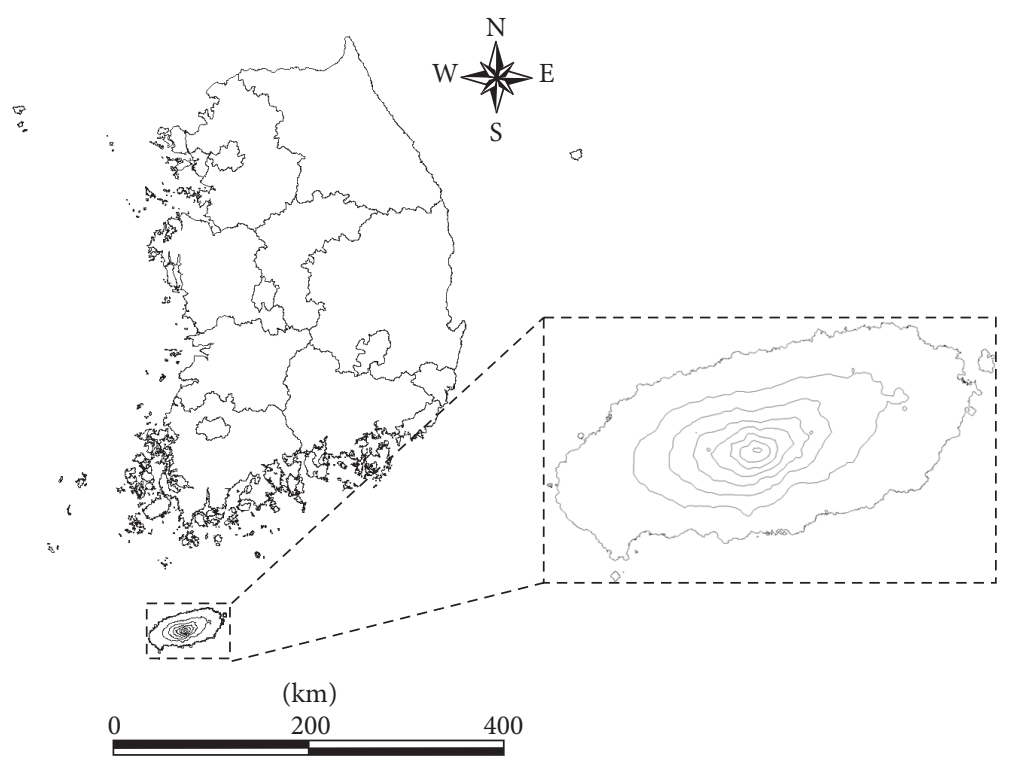

FIgURE 1: Location of the Jeju Island, Korea (the contour lines over the Jeju Island represent the $250 \mathrm{~m}$ altitude interval).

A radar measures the rain rate within the atmosphere in the form of radar reflectivity. The relationship between the radar rain rate $(R)$ and the radar reflectivity $(Z)$ is then quantified by the so-called $Z-R$ relationship. The $Z-R$ relationship varies depending on the storm type [12]; for example, Jones [13] proposed $Z=486 R^{1.37}$ for thundershowers, $Z=380 R^{1.24}$ for rain showers, and $Z=313 R^{1.25}$ for continuous rain. Blanchard [14] proposed $Z=31 R^{1.71}$ for orographic rain, and $Z=300 R^{1.4}$ was proposed for convective rain [15]. The Korea Meteorological Administration (KMA) uses the equation proposed by Marshall and Palmer [16], $Z=200 R^{1.6}$, which is proper for stratiform rainfall.

As the rainfall at Hallasan Mountain is strongly affected by the orographic effect, the relationship between the radar rain rate and the radar reflectivity may not remain unchanged over the entire altitudinal range; that is, the $Z-R$ relationship may vary at different altitudes. The $Z-R$ relationship derived at different altitudes may also represent the orographic effect at Hallasan Mountain. To prove this hypothesis, this study is going to analyze the radar data collected over Jeju Island when Typhoon Nakri passed the island in 2014. In particular, the $Z-R$ relationships will be derived and compared at different altitudes using the AWS rain gauge rain rate data and the radar reflectivity data. Additionally, the areal-average rain rate data estimated by the Marshall-Palmer equation, currently used in Korea, will be compared with the new $Z-R$ relationships that are derived at different altitudes.

This manuscript is composed of six sections as follows. In addition to Introduction and Conclusion, an explanation of Hallasan Mountain and Typhoon Nakri is covered in Section 2; Section 3 covers the explanation of the radar and rain gauge data; Section 4 explains the derivation of the $Z-R$ relationships at different altitudes and their comparison; and, lastly, Section 5 covers the comparison between the total rainfall amounts estimated using the Marshall-Palmer equation and the $Z-R$ relationships derived at different altitudes over the Hallasan Mountain.

\section{Study Area and Rainfall Event}

2.1. Jeju Island and Hallasan Mountain. Jeju Island is the biggest island in Korea and is located in the southernmost region of the Korean Peninsula. Jeju Island is composed of a main island, eight inhabited islands, and 55 uninhabited islands. The shape of the island is elliptical, comprising a major axis length of $73 \mathrm{~km}$ along the east-west direction and a minor axis length of $31 \mathrm{~km}$ along the north-south direction. The total area of Jeju Island is $1,848 \mathrm{~km}^{2}$, and the coastal area with an altitude less than $200 \mathrm{~m}$ above the sea level covers $55.3 \%$ of the island's total area. Figure 1 shows Jeju Island and its administrative districts.

Hallasan Mountain is located at the center of Jeju Island. The height of the mountain is $1,950 \mathrm{~m}$. Hallasan Mountain has a gentle slope of approximately $3^{\circ}$ along the east-west direction and a steeper slope of approximately $5^{\circ}$ along the north-south direction (Jeju Special Self-Governing Province, http://www.jeju.go.kr).

2.2. Typhoon Nakri. The rainfall event considered in this study is Typhoon Nakri, the 12th typhoon of 2014. Typhoon Nakri was generated in the Pacific Ocean near the Philippines on July 30, and it arrived at Jeju Island on August 1 [17]. Originally a mid-sized typhoon, Typhoon Nakri had become very weak during its approach toward Jeju Island, and it was downgraded to a tropical depression after it passed the island; however, the impact of Typhoon Nakri was huge, especially regarding Jeju Island. When the typhoon arrived at Jeju Island, its central pressure and maximum wind velocity were 980 hpa and $25 \mathrm{~m} / \mathrm{s}$, respectively. Figure 2 shows a composite radar image over the Korean Peninsula. 


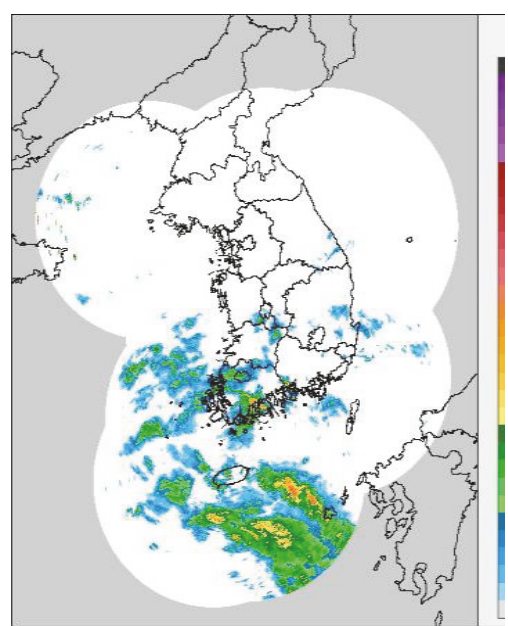

2014/08/02/00:00

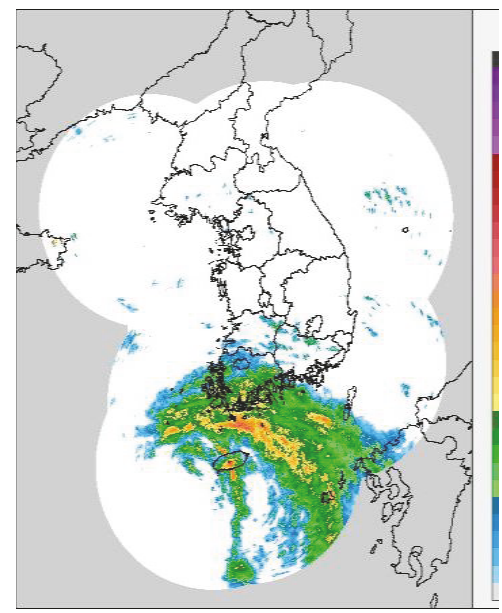

2014/08/02/09:00

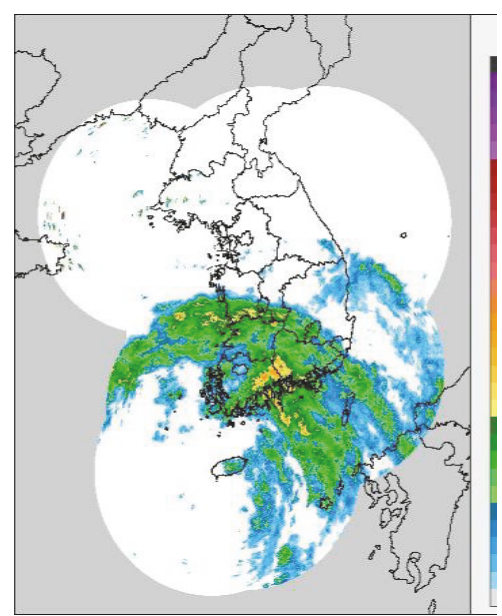

2014/08/02/18:00

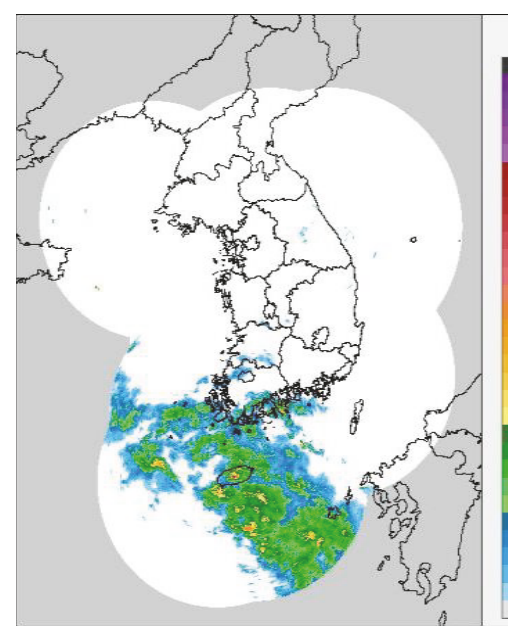

2014/08/02/03:00

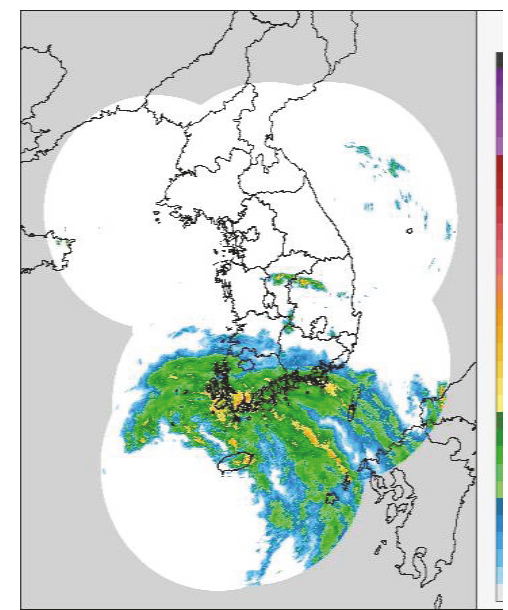

2014/08/02/12:00

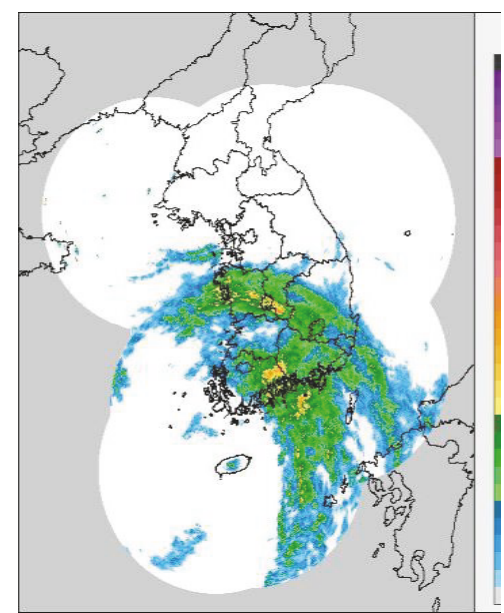

2014/08/02/21:00

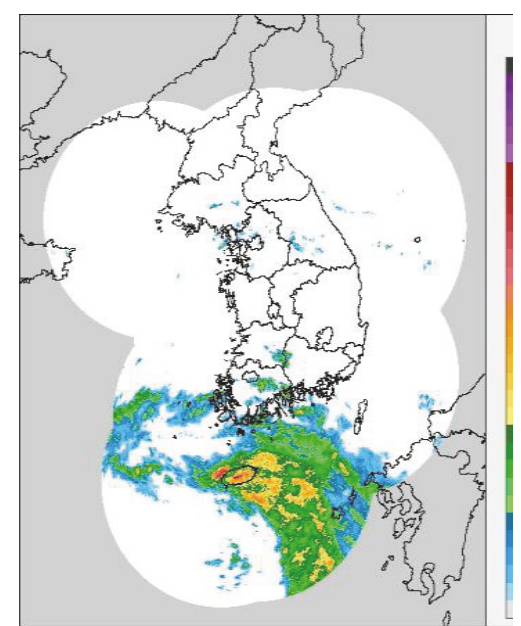

2014/08/02/06:00

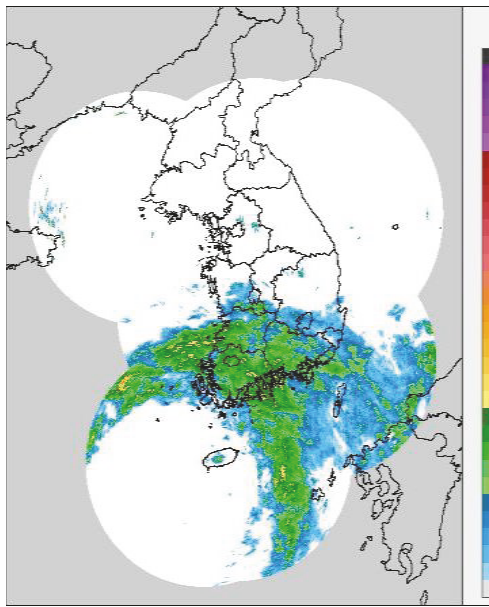

2014/08/02/15:00

FIgURE 2: Synthetic radar image around the Korean Peninsula during the Typhoon Nakri in 2014. 
TABLE 1: Major specification of the Gosan and Seongsan radars.

\begin{tabular}{lcc}
\hline Radar type & $\begin{array}{c}\text { Gosan radar } \\
\text { S-band }\end{array}$ & $\begin{array}{c}\text { Seongsan radar } \\
\text { S-band }\end{array}$ \\
\hline Transmitter & Klystron & $2,755 \mathrm{MHz}$ \\
Transmitting tube & $2,825 \mathrm{MHz}$ & $750 \mathrm{~kW}$ \\
Frequency & $750 \mathrm{~kW}$ & \\
Peak power & & $1.0 \mu \mathrm{s}$ \\
\hline Receiver & $1.0 \mu \mathrm{s}$ & $4.5 \mu \mathrm{s}$ \\
Pulse width & $4.5 \mu \mathrm{s}$ & $250 \sim 1,200 \mathrm{~Hz}$ \\
$\quad$ Short & & $250 \sim 350 \mathrm{~Hz}$ \\
$\quad$ Long & $250 \sim 1,200 \mathrm{~Hz}$ & $8 \mathrm{MHz}$ \\
PRF & $250 \sim 350 \mathrm{~Hz}$ \\
$\quad$ Short pulse & $8 \mathrm{MHz}$ & \\
$\quad$ Long pulse & & $95 \mathrm{~dB}$ \\
Occupied bandwidth & $95 \mathrm{~dB}$ & $10 \mathrm{MHz}$ \\
Antenna & $10 \mathrm{MHz}$ & $8.5 \mathrm{~m}$ \\
Dynamic range & $8.5 \mathrm{~m}$ & $1.0^{\circ}$ \\
Intermediate frequency & $1.0^{\circ}$ & $45 \mathrm{~dB}$ \\
Antenna diameter & $45 \mathrm{~dB}$ & \\
Beam width & & \\
Antenna gain & & \\
\hline
\end{tabular}

\section{Rainfall Observation}

3.1. Radars. For the purpose of typhoon tracking, the KMA operates two radars on Jeju Island, the Gosan and the Seongsan radars. The Gosan radar, originally a C-band radar, was introduced in 1991 but was replaced by an S-band radar in 2006. The Seongsan radar, also an S-band radar, was introduced in 2006 to supplement the Gosan radar with the particular purpose of the removal of the blind spot caused by Hallasan Mountain. Both radars have been designed with an observation radius of $240 \mathrm{~km} \times 240 \mathrm{~km}$ and a resolution of $1 \mathrm{~km} \times 1 \mathrm{~km}$. The major specifications of the Gosan and Seongsan radars are summarized in Table 1.

The locations of the Gosan and Seongsan radars are shown in Figure 3. Figure 3 also shows the radar beam blockage, as an example, for the $1.5 \mathrm{~km}$ CAPPI at 07:00 on August 2, 2014. Using both radars, it is possible to observe the entire island including Hallasan Mountain.

3.2. Rain Gauges. In 1990, the KMA started to introduce the AWSs onto Jeju Island [10], and 24 AWSs are currently operated on the island [18]. Among them, a total of 16 rain gauges are located in the coastal area with an altitude less than $250 \mathrm{~m}$ above the sea level, four are located between $250 \mathrm{~m}$ and $500 \mathrm{~m}$, two are located between $750 \mathrm{~m}$ and $1,000 \mathrm{~m}$, one is located between $1,250 \mathrm{~m}$ and $1,500 \mathrm{~m}$, and one is located at $1,500 \mathrm{~m}$ or higher. The locations of the rain gauges are presented in Figure 4. As can be seen from this figure, the rain gauges are well distributed across Jeju Island. More than half of the total rain gauges are located in the coastal area $(0 \mathrm{~m}$ to $250 \mathrm{~m})$, and relatively less are in the mountain area. Also, more rain gauges are located on the northern slope of Hallasan Mountain than on the southern slope, which is due to the steepness of the latter.

\section{Decision of $Z-R$ Relationships at Different Altitude Zones}

4.1. Preparation of Radar Reflectivity Data. This study used the composite radar reflectivity data arising from both the Gosan and Seongsan radars. A total of eight composite radar reflectivity fields were prepared from an altitude of $250 \mathrm{~m}$ to $2,000 \mathrm{~m}$ at intervals of $250 \mathrm{~m}$. From each radar, $0.25 \mathrm{~km}$ CAPPI, $0.50 \mathrm{~km}$ CAPPI, $0.75 \mathrm{~km}$ CAPPI, $1.00 \mathrm{~km}$ CAPPI, $1.50 \mathrm{~km}$ CAPPI, $1.75 \mathrm{~km}$ CAPPI, and $2.00 \mathrm{~km}$ CAPPI data were prepared and utilized to create the composite field at each altitude. When the data from both radar systems were available, their arithmetic mean was calculated to compute the representative reflectivity. In case that the radar reflectivity from only one radar is available, this reflectivity was assumed to be the representative value in this study.

Every $10 \mathrm{~min}$, eight composite radar reflectivity fields were prepared and used to generate the composite field for the entirety of Jeju Island, and Figure 5 shows how it was constructed. As the altitude increased, a much smaller toroidal radar composite data field was selected. Lastly, by combining these donut-shaped fields, the full composite radar reflectivity field for the entire island could be created. The right-hand-side panel in Figure 5 shows the resulting composite radar reflectivity field of the entire island; so, the radar reflectivity in this figure represents that near the ground with a maximum altitude difference of $250 \mathrm{~m}$.

\subsection{Parameter Estimation of Z-R Relationship}

4.2.1. $0 \mathrm{~m}$ to $250 \mathrm{~m}$. The $Z$ - $R$ relationship is used to convert the radar reflectivity into the rain rate [19]. Radar measures the intensity of the echo generated from the raindrops in 


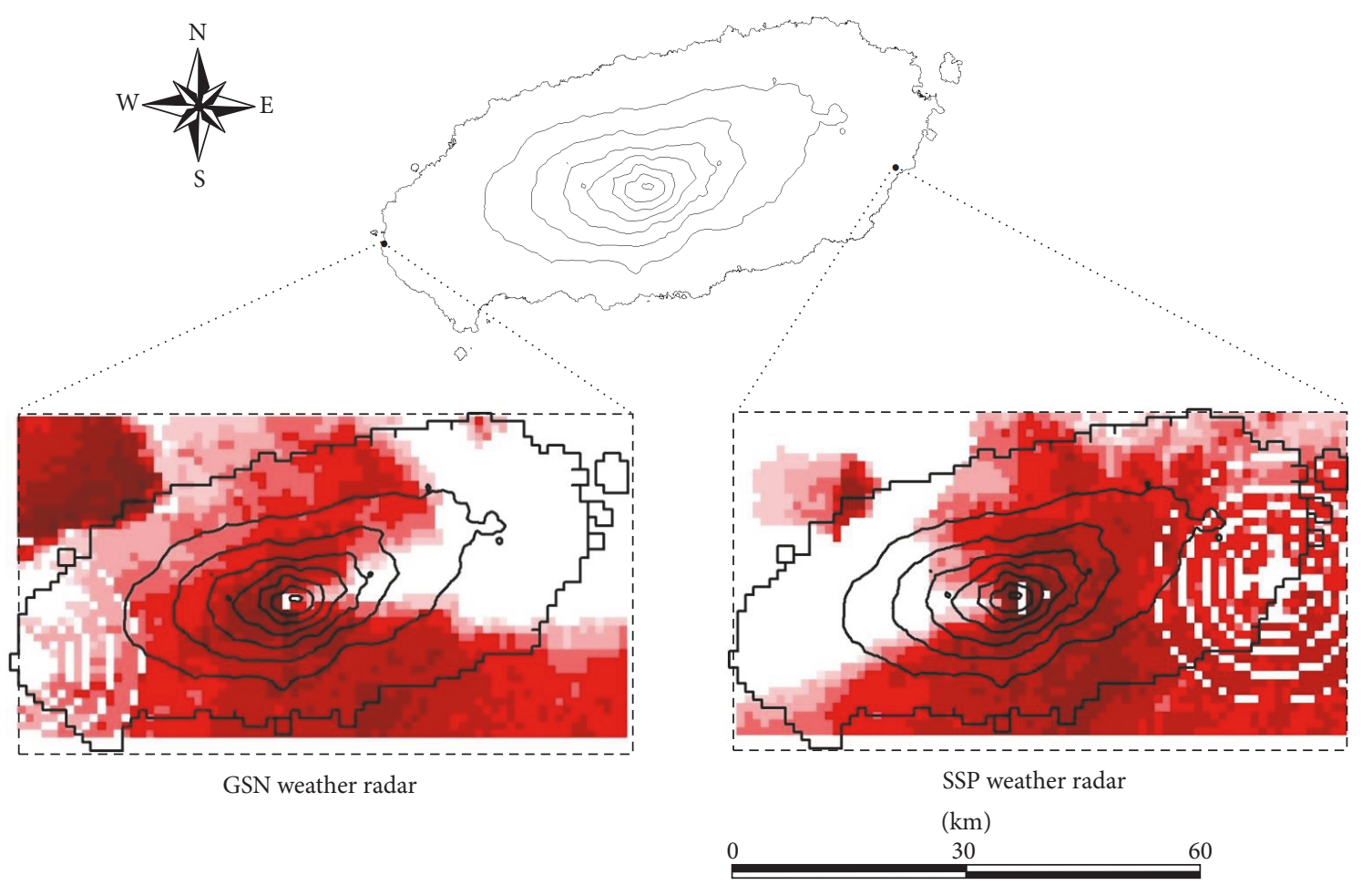

FIGURE 3: Location of the Gosan and Seongsan radars and their radar beam blockages for the $1.5 \mathrm{~km}$ CAPPI data (during the Typhoon Nakri, 07:00 Aug. 2, 2014).

the air, which is the radar reflectivity $(Z)$. That is, $Z$ can be expressed as follows:

$$
Z=\int N(D) D^{6} d D
$$

where $D$ represents the diameter of a raindrop and $N(D)$ is the number of raindrops with diameter $(D \sim D+d D)$ in the unit volume. $Z$ has the unit of $\mathrm{mm}^{6} / \mathrm{m}^{3}$. It is also possible to express the rain rate $(R, \mathrm{~mm} / \mathrm{h})$ as follows:

$$
R=\frac{\pi}{6} \int N(D) D^{3} V(D) d D
$$

where $V(D)$ is the vertical speed of a rain drop. By combining (1) and (2), one can derive the $Z-R$ relationship:

$$
Z=A R^{b}
$$

where $A$ and $b$ are parameters to be estimated using the observed data. Using this relationship, one can estimate the rain rate for given radar reflectivity.

In this study, the $Z-R$ relationship was derived independently for each altitude zone; therefore, the $Z-R$ relationship at one altitude zone (e.g., $0 \mathrm{~m}$ to $250 \mathrm{~m}$ ) can differ from that at another (e.g., $750 \mathrm{~m}$ to $1,000 \mathrm{~m}$ ). To determine the parameters (i.e., $A$ and $b$ ) of the $Z-R$ relationship, the radar data and the rain gauge data were compared, as shown in Figure 6.

As can be seen in Figure 6, 13 rain gauges are located at the altitude zone of $0 \mathrm{~m}$ to $250 \mathrm{~m}$. Among them, two rain gauges (\#185 and \#188) were excluded in the analysis because the radar reflectivity data were not available. Most of the scatter plots between the radar reflectivity and the rain gauge rain rate showed that strong linearity exists on a log-log paper, with some exceptions like \#328, \#781, and $\# 885$. Also, at location $\# 779$, the trend was not obvious as only a few data were available. In this study, a total of nine rain gauges were therefore considered for deriving the $Z-R$ relationship. The parameters of the $Z-R$ relationship were estimated based on the least squares method (LSM). The resulting $Z-R$ relationship is compared in Figure 7(a) with the observed data used for its estimation. The Marshall-Palmer equation, $Z=200 R^{1.6}$, is also compared in Figure $7(\mathrm{a})$.

As can be seen in Figure 7(a), even though the $Z-R$ relationship was determined based on the LSM, its slope did not seem to fit what was observed; rather, the slope of the Marshall-Palmer equation seemed to be more suitable. In this study, the $Z-R$ relationship was therefore estimated again after its slope was fixed to 1.6, just like the adjustment regarding the Marshall-Palmer equation (Figure 7(b)). Interestingly, the newly derived $Z-R$ relationship seemed to be much more suitable than the other two, and this was also the same for the other altitude zones. As a result, the $Z-R$ relationship for the altitude zone of $0 \mathrm{~m}$ to $250 \mathrm{~m}$ was determined to be $Z=11.4 R^{1.6}$.

4.2.2. Other Altitude Zones Where Rain Gauges Are Available. Just four rain gauges were available at the altitude zone of $250 \mathrm{~m}$ to $500 \mathrm{~m}$. The linear relation between the radar reflectivity and the rain gauge rain rate was strong at two rain gauge stations (\#727 and \#751); however, at two other 


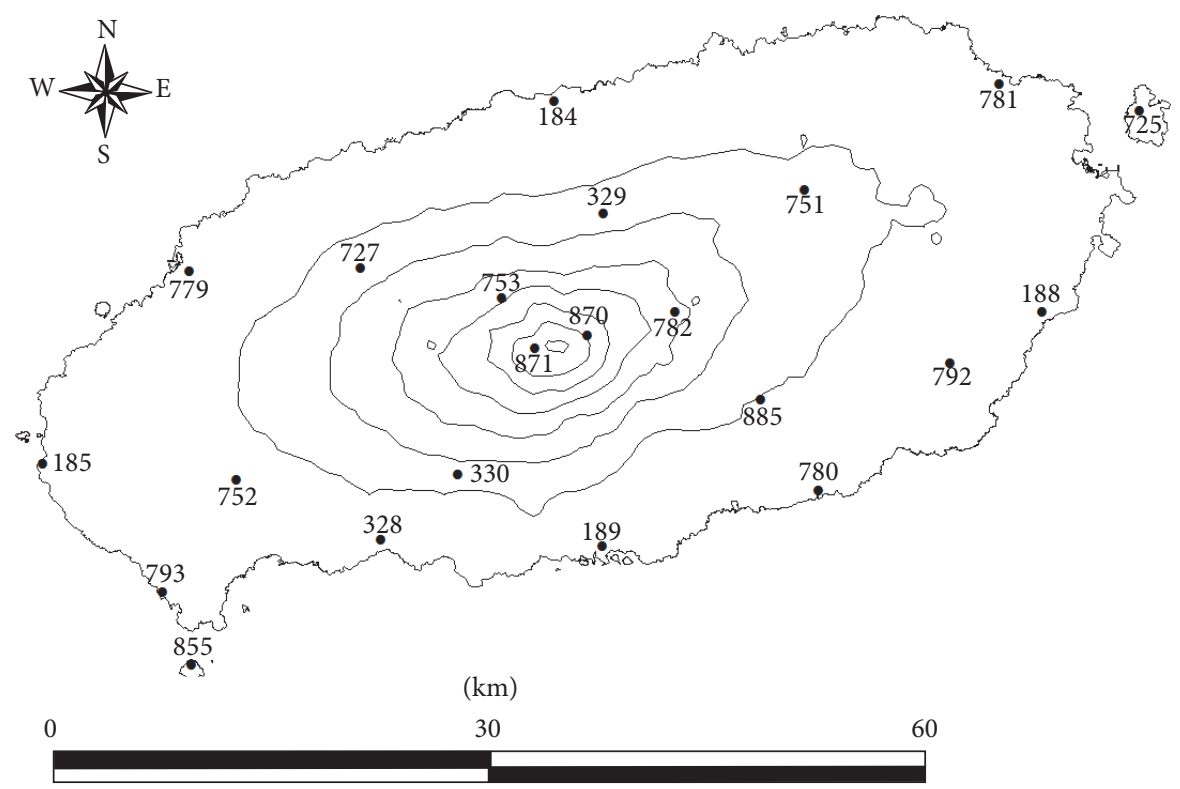

Figure 4: Rain gauges over the Jeju Island (184 (ID number), Jeju (place name), 185, Gosan, 188, Seongsan, 189, Seogwipo, 328, Jungmun, 329, Ara, 330, Hawon, 725, Udo, 727, Yusuam, 751, Seonheul, 752, Seogwang, 753, Eorimok, 779, Hallim, 780, Namwon, 781, Gujwa, 782, Seongpanak, 792, Pyoseon-myeon, 793, Moseulpo, 855, Gapado, 870, Jindallebat, 871, Witse Oreum, 885, Typhoon Center).
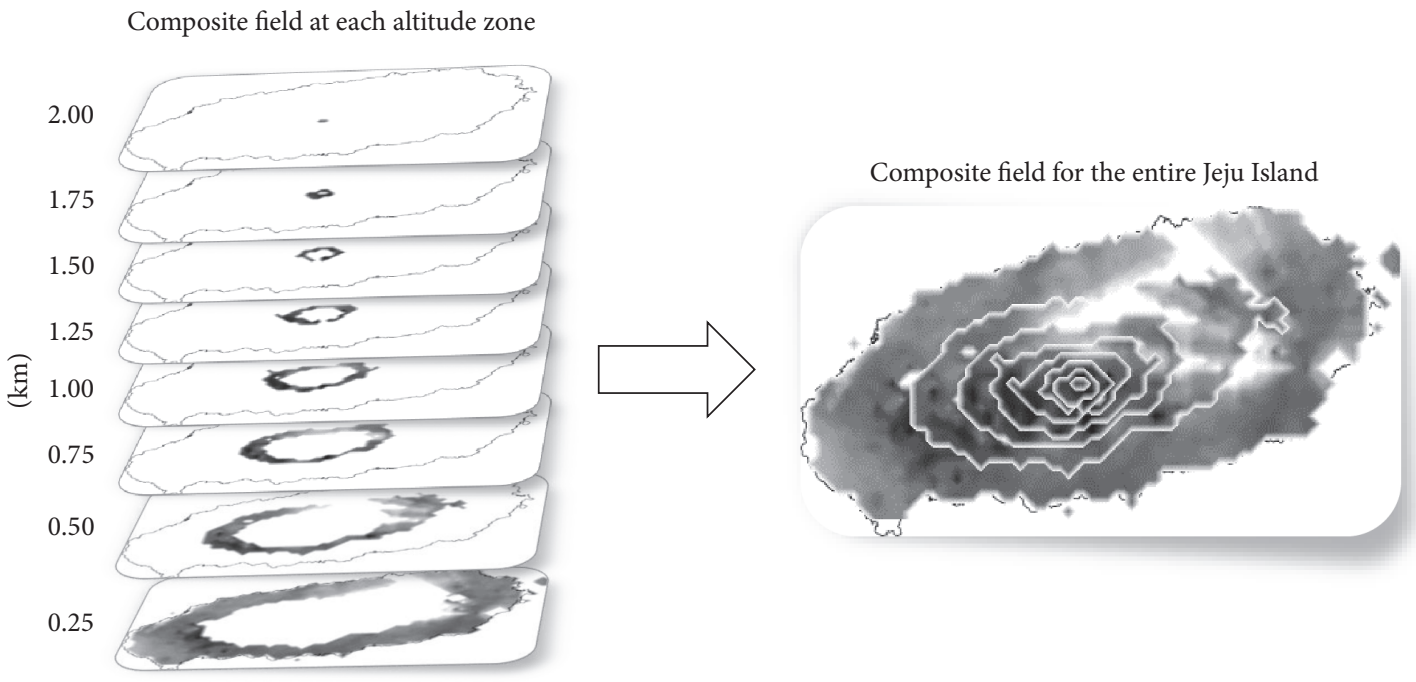

FIGURE 5: Construction of radar reflectivity field over the Jeju Island using the radar CAPPI data (radar data observed at 2014/08/02/05:00).

rain gauge stations (\#329 and \#330), no obvious trend could be detected. In this altitude zone, only two rain gauges, $\# 727$ and $\# 751$, were therefore considered for the determination of the $Z-R$ relationship. The resulting $Z-R$ relationship is $Z=$ $7.4 R^{1.6}$.

Only two rain gauges ( $\# 753$ and \#782) were available at the altitude zone of $750 \mathrm{~m}$ to $1,000 \mathrm{~m}$. A linear trend was obvious at these two rain gauge stations, both of which could be used for the determination of the $Z-R$ relationship. The resulting $Z$ - $R$ relationship is $Z=1.8 R^{1.6}$.

At the altitude zone of $1,250 \mathrm{~m}$ to $1,500 \mathrm{~m}$, only one rain gauge (\#870) was available, for which a linear trend could be found between the radar reflectivity and the rain gauge rain rate. The resulting $Z-R$ relationship is $Z=4.56 R^{1.6}$.

At the altitude zone of $1,500 \mathrm{~m}$ to $1,750 \mathrm{~m}$, only one rain gauge (\#871) was available, for which a linear trend could be found between the radar reflectivity and the rain gauge rain rate. The resulting $Z-R$ relationship is $Z=31.12 R^{1.6}$.

\subsubsection{Interpolation for Those Altitude Zones Where No Rain} Gauge Is Available. As rain gauges were not available at some altitude zones, it was impossible to determine the $Z-R$ relationship by solely relating the radar reflectivity and the rain gauge rain rate. Among the eight altitude zones, the 


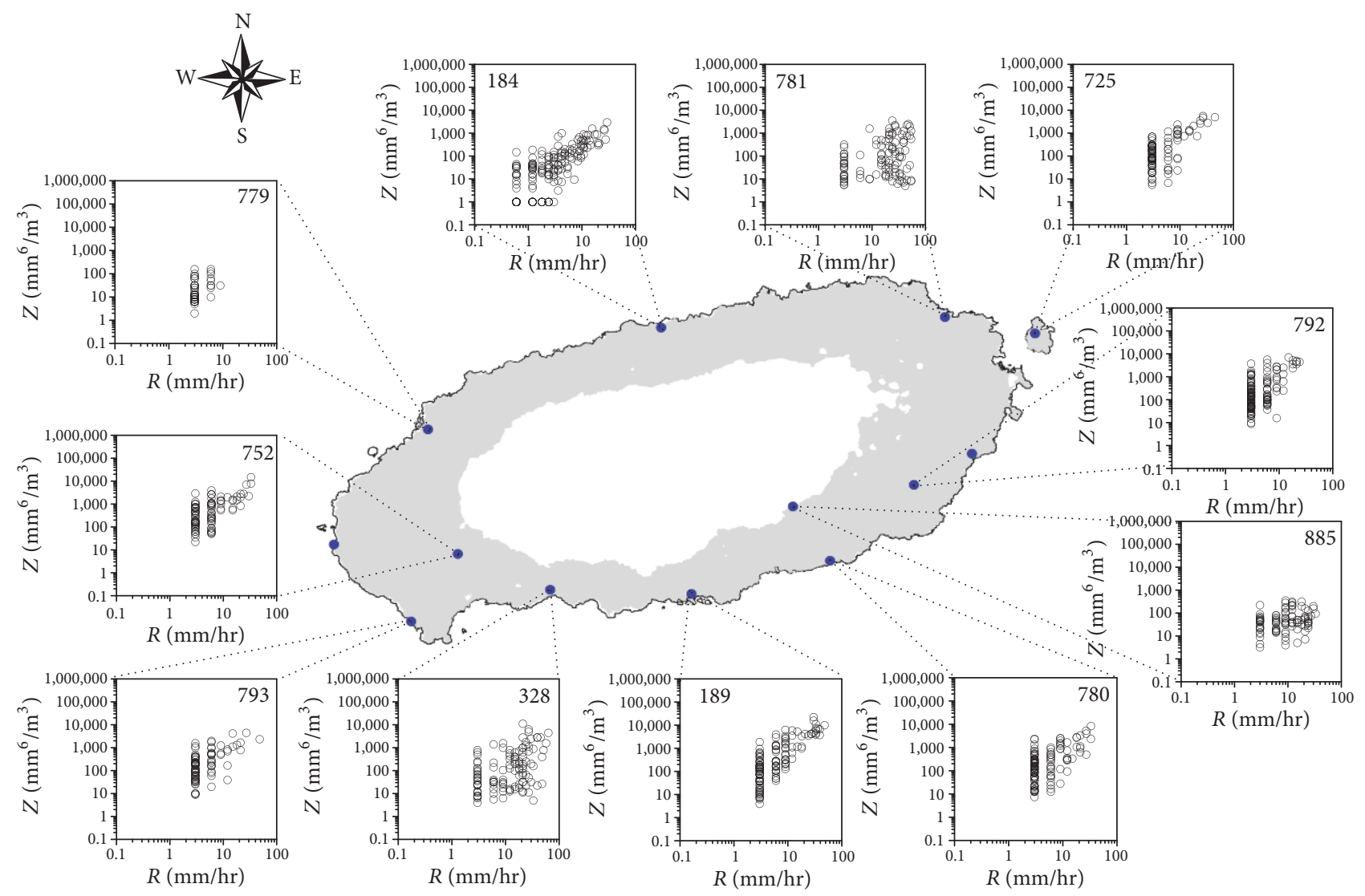

$(\mathrm{km})$

\begin{tabular}{ll}
0 & 30 \\
\hline
\end{tabular}

FIGURE 6: Scatter plots of rain gauge rain rate and radar reflectivity at AWS locations within the 0-250 m altitude zone.

$Z-R$ relationships were determined directly by analyzing the observed data. Figure 8 compares the $Z-R$ relationships with respect to the altitude. For those altitude zones in which rain gauges were not available, the parameter $A$ was estimated by considering the trend of the $A$ values from five altitude zones. The estimated parameter $A$ for the altitude zones of $500 \mathrm{~m}$ to $750 \mathrm{~m}, 1,000 \mathrm{~m}$ to $1,250 \mathrm{~m}$, and $1,750 \mathrm{~m}$ to $2,000 \mathrm{~m}$ is $5.0,3.2$, and 57.7, respectively.

4.2.4. Change of Z-R Relationships and Orographic Effect. As can be seen in Figure 8, the $Z-R$ relationships derived for each altitude zone during Typhoon Nakri differ dramatically. Also, in all cases, the parameter $A$ is much smaller than the parameter of the Marshall-Palmer equation. This result indicates that the rain rate is much higher compared to the strength of the radar reflectivity.

It was also found that the parameter $A$ of the $Z-R$ relationship was recorded the least at an altitude around $1,000 \mathrm{~m}$ and the highest at an altitude around 1,750 m. That is, the parameter $A$ from the coastal area (low altitude zone) to the mountain area (high altitude zone) did not show any consistent increasing or decreasing trends. The parameter $A$ was decreased beyond the coastal area, showing a minimal value at an altitude around 1,000 $\mathrm{m}$ before it increased again.

As the change of the parameter $A$ is so large, from 11.4 to 1.8 and then up to 31.1 , it cannot be regarded as a problem from the observed data or the parameter estimation. Alternatively, the decrease of the parameter $A$ in the low altitude zone may be explained by the sea breeze front [20], which generally occurs in the coastal area. As the sea breeze includes the ascending air current, a convective cloud can be developed easily when the humidity is high. The orographic effect may be a reason to increase the parameter $A$ in the high altitude zone. The rain rate can be increased due to the ascending air current that follows the mountain slopes, which can also be strengthened when both the humidity and the wind velocity are high [1-6].

The above results are also well supported by the comparison result of the drop size distribution (DSD) [21]. In their study [21], the DSD data were measured from 14:20 to $16: 20$, July 1, 2012, using seven PARSIVEL (PARticle SIze and VELocity) disdrometers from the altitude $200 \mathrm{~m}$ to $1,000 \mathrm{~m}$. Their observed data were summarized by the DSD distributions, which were different at each altitude. In fact, 


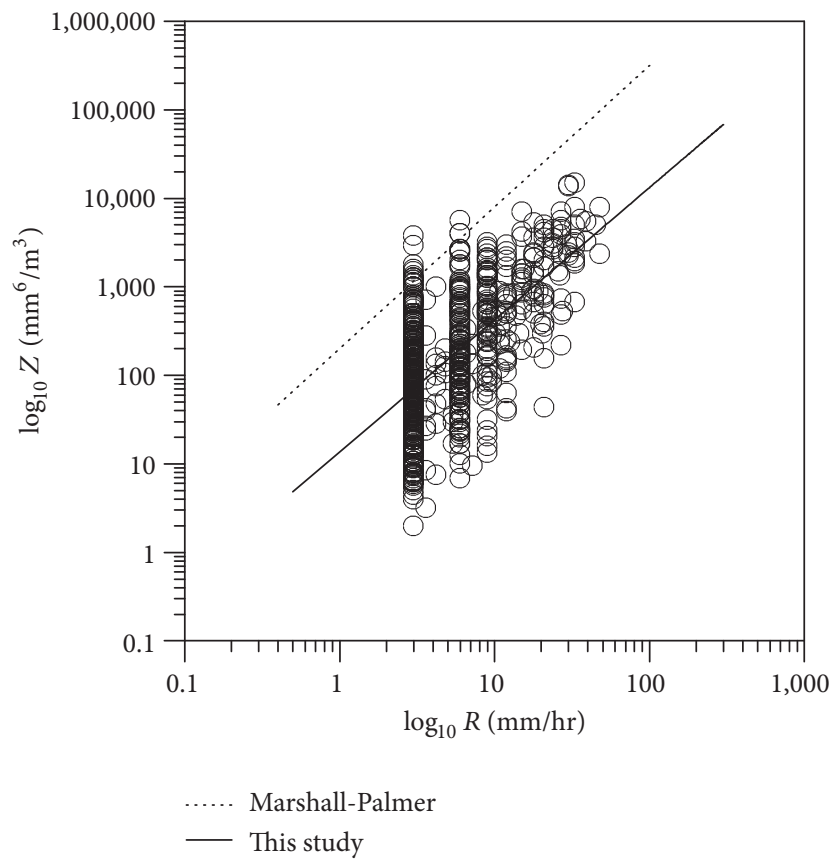

(a) $b=1.49$

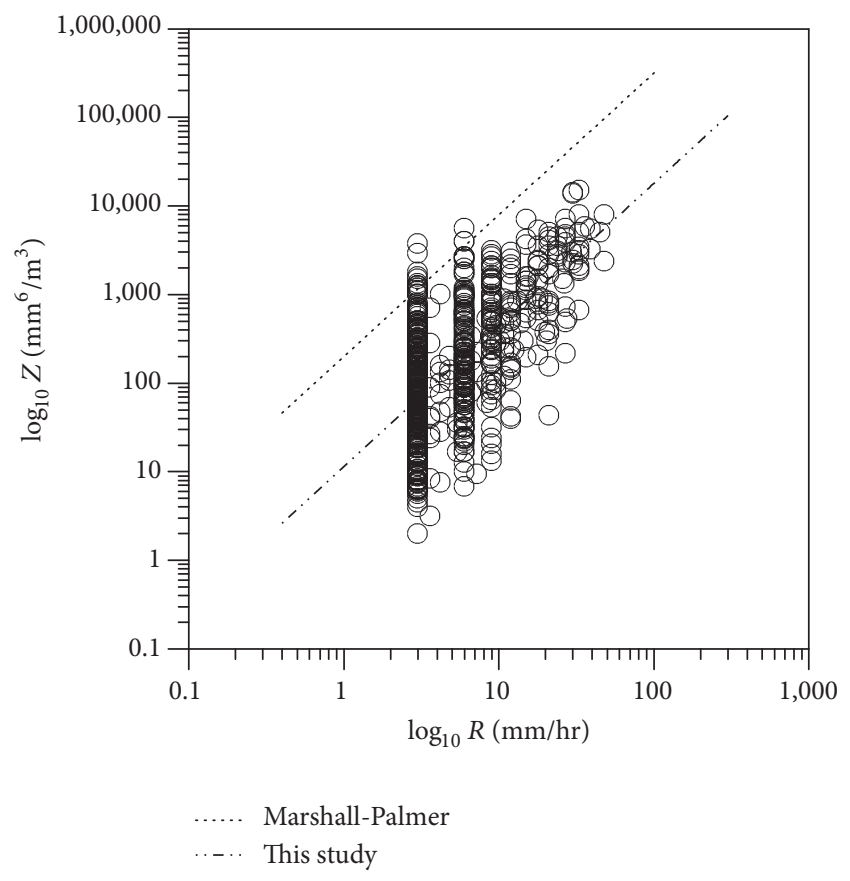

(b) $b=1.60$

Figure 7: $Z-R$ relationships estimated for the $0-250 \mathrm{~m}$ altitude zone.

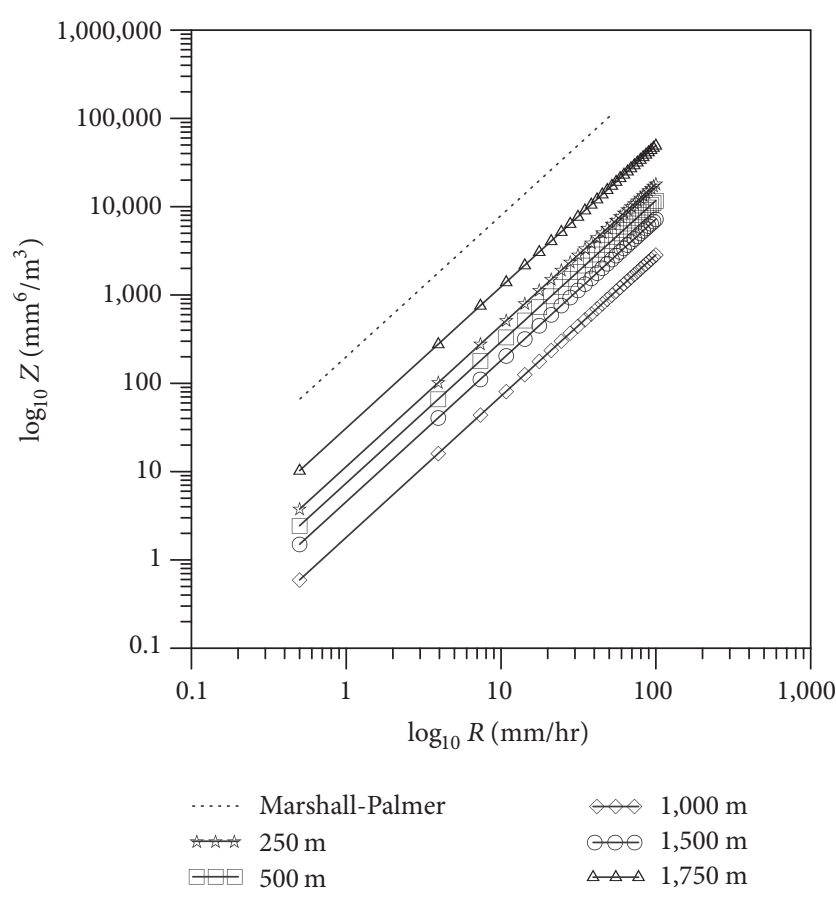

FIGURE 8: $Z$ - $R$ relationships estimated for each altitude zone.

their DSD distributions can be used to estimate the parameter $A$ of the $Z-R$ relationship [16]. As the DSD distributions are all very similar to the exponential distribution, their decay patterns can be used to compare the parameter $A$ of the $Z-R$ relationship. For example, at the altitude $200 \mathrm{~m}$, the DSD distribution shows a fast decay pattern but a slow one for the altitude $1,000 \mathrm{~m}$. This difference indicates that the parameter $A$ of the $Z-R$ relationship is higher for the altitude $200 \mathrm{~m}$ than that for the altitude $1,000 \mathrm{~m}$. This result is well coincident with that of this study.

4.2.5. Possible Difference between Upslope and Downslope Sides. Additionally, authors tried to derive and compare the $Z-R$ relationship for the upslope and downslope sides of the Hallasan Mountain considering the storm movement during Typhoon Nakri. However, due to the limit of rain gauges available, the $Z-R$ relationship could be derived at only two altitude zones, $250 \mathrm{~m}$ and $1,000 \mathrm{~m}$ (see Figure 9). In this figure, the northern part indicates the downslope side and the southern part the upslope side.

Before all, it should be mentioned that the newly derived $Z-R$ relationships are found a bit different from those for the entire data. This result indicates that the rainfall characteristics at the upslope side were different from those at the downslope side. In this special case, the difference was smaller at the high altitude zone. It is also interesting to note that the positions of the newly derived $Z-R$ relationships were different at the two altitude zones. At the low altitude zone, the newly derived $Z-R$ relationship for the upslope side was located higher than that at the downslope side. However, at the high altitude zone, the newly derived $Z-R$ relationship for the upslope side was located lower.

The above results are very interesting and well correspondent to the other studies $[22,23]$. However, in this study, these results could not be generalized as only limited cases were available. Also, the difference observed in the upslope and downslope sides did not seem to be so significant compared with the difference found at different altitude zones. Thus, 


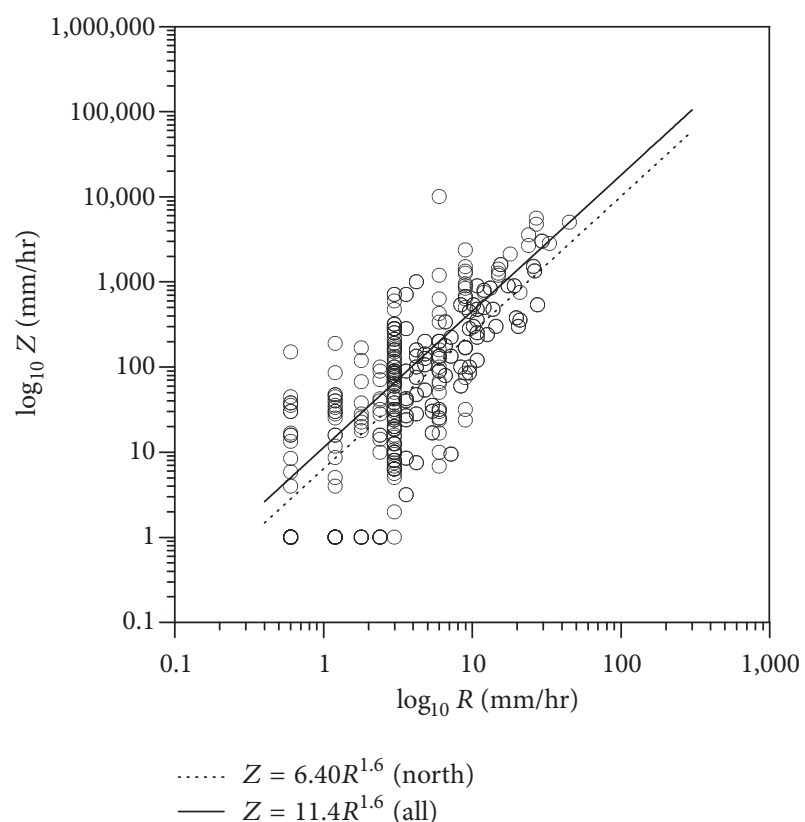

(a) $250 \mathrm{~m}$ (North)

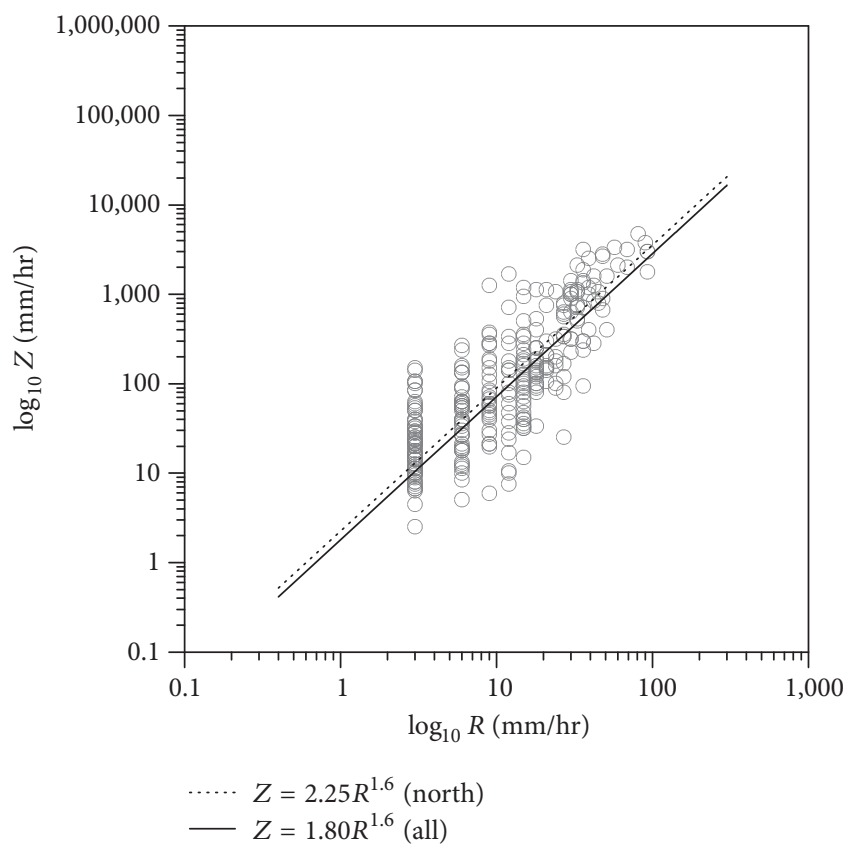

(c) $1,000 \mathrm{~m}$ (North)

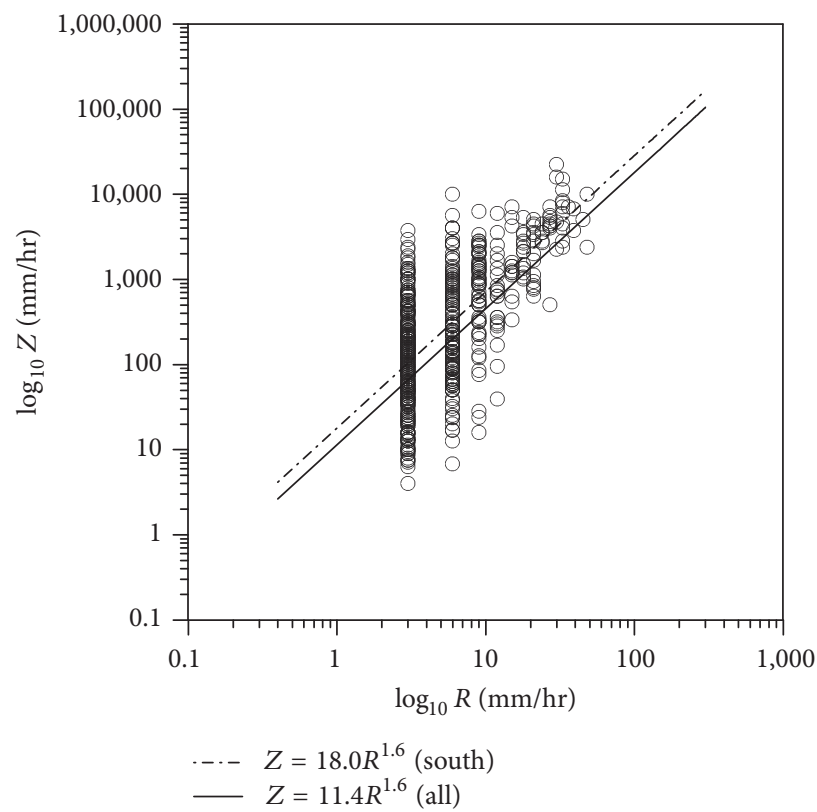

(b) $250 \mathrm{~m}$ (South)

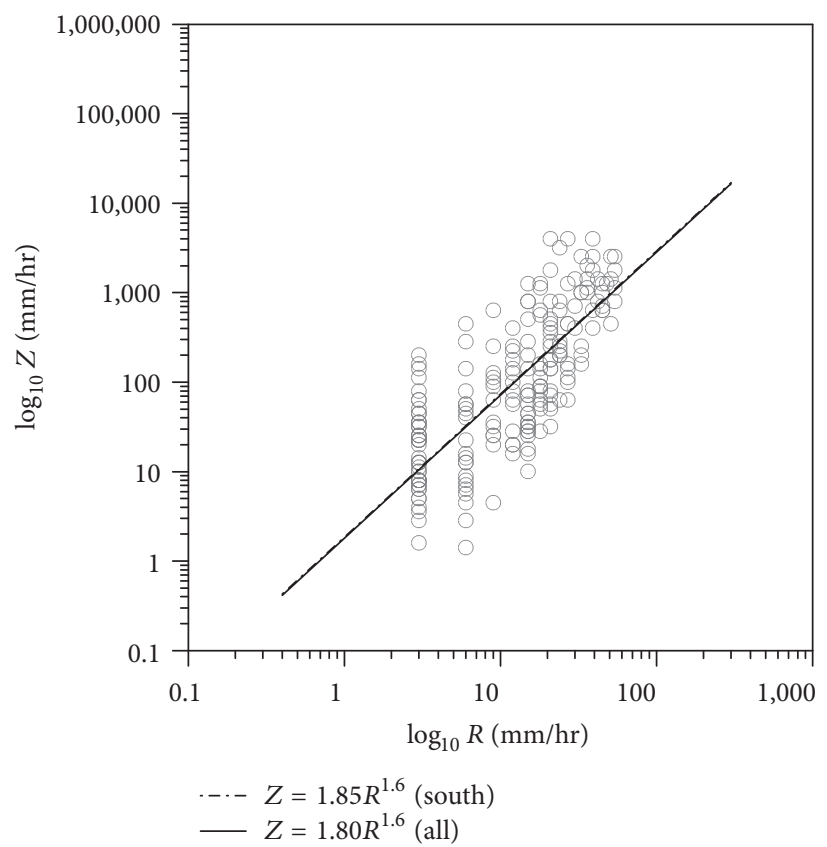

(d) $1,000 \mathrm{~m}$ (South)

FIGURE 9: Comparison of the $Z-R$ relationships derived for northern and southern parts of the Jeju Island. In this figure, the solid line represents the $Z-R$ relationship derived using all the data available and the dotted lines for northern and southern parts only.

in this study, further analysis was done using only the $Z-R$ relationship derived at each altitude zone.

\section{Areal-Average Rain Rate over Jeju Island during Typhoon Nakri}

In Korea, the $1.5 \mathrm{~km}$ CAPPI data is generally used to generate the rain rate data. The altitude of $1.5 \mathrm{~km}$ was determined to minimize the beam blockage by considering the radar network and the topography over the Korean Peninsula. The effects of the bright band and ground echo could also be avoided by adopting this altitude as the standard for the use of the radar data [24]. The Marshall-Palmer equation is generally used to convert the $1.5 \mathrm{~km}$ CAPPI radar reflectivity data into the radar rain rate [25]. In this study, an additional $Z-R$ relationship was determined using the $1.5 \mathrm{~km}$ CAPPI radar reflectivity and rain gauge data for the entirety of Jeju 


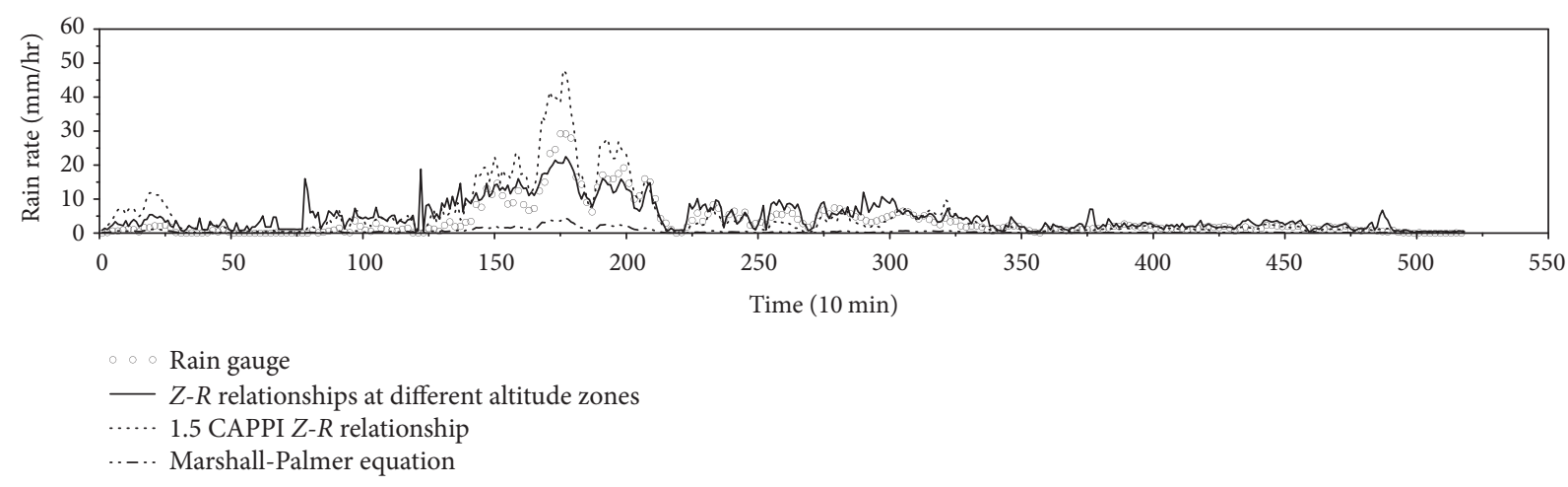

(a) Areal-average rain rates

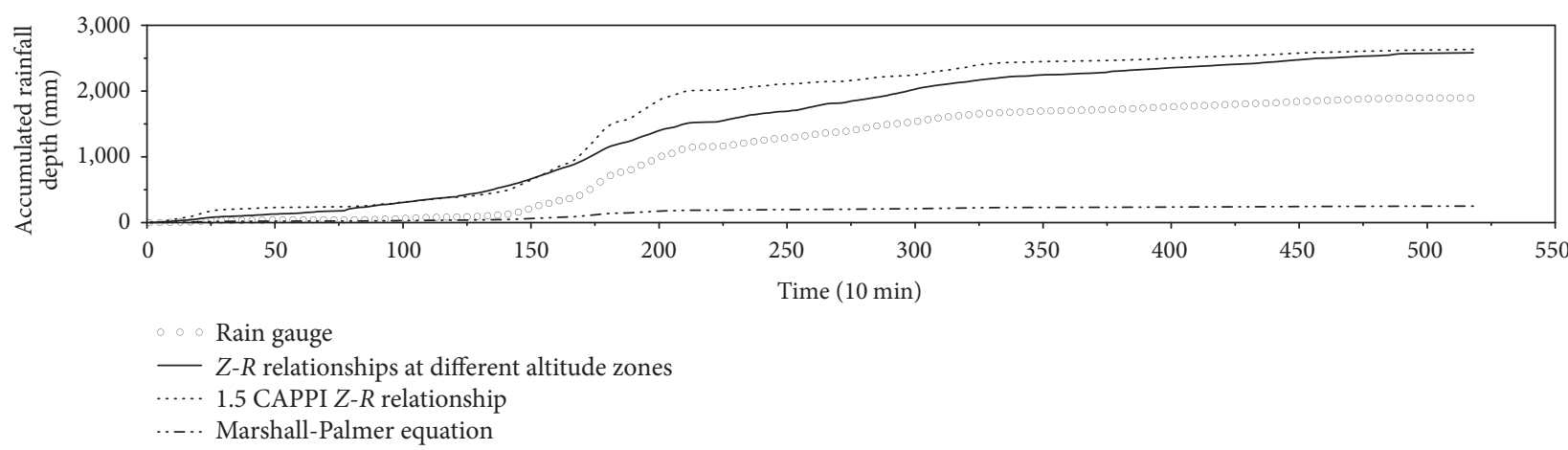

(b) Accumulated

FIGURE 10: Comparison of (a) areal-average rain rates estimated by rain gauge, $Z$ - $R$ relationships at difference altitude zones, $1.5 \mathrm{~km} C A P P I$ $Z-R$ relationship and Marshall-Palmer equation, and (b) their accumulations.

Island during Typhoon Nakri. The resulting $Z-R$ relationship is $Z=4.44 R^{1.6}$.

The $Z-R$ relationships that were determined at different altitude zones were applied to each altitude of the CAPPI data, and the $Z-R$ relationships determined with the $1.5 \mathrm{~km}$ CAPPI data were applied to the $1.5 \mathrm{~km}$ CAPPI data to convert the radar reflectivity into the radar rain rate. The MarshallPalmer equation was also applied to the $1.5 \mathrm{~km}$ CAPPI radar reflectivity data. The radar rain rate data were then used to estimate the areal-average rain rate over the entirety of Jeju Island. The results are compared in Figure 10. The arealaverage rain rate that was estimated using the rain gauge data is also compared in the same figure.

As can be found in Figure 10(a), the areal-average rain rate that was estimated using the radar rain rate with the $Z-R$ relationships at different altitudes is most similar to the estimate for which the rain gauge data were used. The areal-average rain rate that was estimated using the $1.5 \mathrm{~km}$ CAPPI $Z-R$ relationship shows a slightly higher peak rain rate, while the Marshall-Palmer equation seems to underestimate the rain rate. This difference was also found in the comparison of the accumulated areal-average rainfall depth (Figure 10(b)). Particularly, the accumulated rainfall depth during the typhoon which was estimated using the $1.5 \mathrm{~km}$ CAPPI $Z-R$ relationship was $2,633.8 \mathrm{~mm}$, which was approximately $40 \%$ higher than that for which the rain gauge data was used $(1,896.4 \mathrm{~mm})$. The accumulated rainfall depth that was estimated using the $Z-R$ relationships at different altitudes $(2,582.5 \mathrm{~mm})$ was also similar to that for which the $1.5 \mathrm{~km}$ CAPPI $Z-R$ relationship was used. As the ground rain gauge could not sufficiently capture the orographic effect, it is believed that the accumulated rain rate estimated by the ground rain gauge was a slight underestimate; alternatively, the estimate for which the Marshall-Palmer equation was applied was approximately $250.5 \mathrm{~mm}$, which was just onetenth of the other estimates. The peak times of the arealaverage rain rate of the three estimates were all found to be similar.

Finally, Table 2 compares the maximum rainfall depths for rainfall durations of 10 minutes and 1 hour; for example, the 10 -minute maximum areal-average rain rates are $5.1 \mathrm{~mm}$ for the rain gauge estimate, $3.7 \mathrm{~mm}$ for the $Z-R$ relationships at corresponding altitude zones, $7.9 \mathrm{~mm}$ for the $1.5 \mathrm{~km}$ CAPPI $Z-R$ relationship, and just $0.7 \mathrm{~mm}$ for the Marshall-Palmer equation. The estimates of the one-hour maximum arealaverage rain rates are $170.8 \mathrm{~mm}$ for the rain gauge estimate, $125.8 \mathrm{~mm}$ for the $Z-R$ relationships at corresponding altitude zones, $251.9 \mathrm{~mm}$ for the $1.5 \mathrm{~km}$ CAPPI $Z-R$ relationship, and just $23.3 \mathrm{~mm}$ for the Marshall-Palmer equation.

\section{Summary and Conclusions}

This study analyzed the radar data for the entirety of Jeju Island which were measured when Typhoon Nakri passed 
TABLE 2: Comparison of maximum areal-average rainfall depth recorded by rain gauge and radar for several rainfall durations.

\begin{tabular}{|c|c|c|c|c|c|}
\hline & \multicolumn{2}{|c|}{10 minutes } & \multicolumn{2}{|r|}{1 hour } & \multirow[b]{2}{*}{$\begin{array}{l}\text { Total depth } \\
\quad(\mathrm{mm})\end{array}$} \\
\hline & $\begin{array}{l}\text { Depth } \\
(\mathrm{mm})\end{array}$ & $\begin{array}{c}\text { Time of } \\
\text { occurrence }\end{array}$ & $\begin{array}{c}\text { Depth } \\
(\mathrm{mm})\end{array}$ & Time of occurrence & \\
\hline Rain gauge & 5.1 & $2014 / 08 / 02 / 06: 30$ & 170.8 & 2014/08/02/07:00 & 1896.4 \\
\hline$Z-R$ relationships at corresponding altitude zones & 3.7 & 2014/08/02/06:40 & 125.8 & 2014/08/02/07:00 & 2582.5 \\
\hline $1.5 \mathrm{~km}$ CAPPI $Z-R$ relationship & 7.9 & $2014 / 08 / 02 / 06: 30$ & 251.9 & 2014/08/02/07:00 & 2633.9 \\
\hline Marshall-Palmer equation & 0.7 & $2014 / 08 / 02 / 06: 30$ & 23.3 & 2014/08/02/07:00 & 250.5 \\
\hline
\end{tabular}

the island in 2014. First, the $Z-R$ relationship to convert the radar reflectivity data into rain rate data was developed for each altitude zone (eight altitude zones from $0 \mathrm{~m}$ to $2,000 \mathrm{~m}$ with $250 \mathrm{~m}$ intervals), and they were compared to consider the possible orographic effect at Hallasan Mountain in Jeju Island. Second, the derived $Z-R$ relationships were applied to the corresponding altitude radar reflectivity data to generate the rain rate field over Jeju Island. This rain rate field was used to derive the areal-average rain rate data for the entirety of Jeju Island, which were also compared with those that were estimated from the application of the Marshall-Palmer equation to the $1.5 \mathrm{~km}$ CAPPI data, which is generally used in Korea. The results can be summarized as follows.

First, the $Z-R$ relationships derived for each altitude zone during Typhoon Nakri show that the exponent $b$ could be assumed as constant; however, the parameter $A$ showed a decreasing trend after the coastal area was passed, with the minimal value shown at an altitude around $1,000 \mathrm{~m}$, followed by another increasing trend. The orographic effect seems to be highest around this altitude.

Second, the areal-average rain rate estimated using the $Z-R$ relationships at corresponding altitudes was found to be most similar to that estimated using the rain gauge data; however, the areal-average rain rate estimated using the MarshallPalmer equation was found to be significantly smaller than that based on the rain gauge data. The accumulated rainfall depth during the typhoon estimated using the MarshallPalmer equation was found to be just one-tenth of the other estimates.

In this study, it was confirmed that the orographic effect at a mountain can be effectively observed by a radar. At Hallasan Mountain, the orographic effect seems to be highest around the altitude of $1,000 \mathrm{~m}$. While generating the radar rain rate field, it was also confirmed that the proper $Z-R$ relationship should be used. However, as this study is just one example of an orographic effect analysis, a generalization of the result may be possible with the inclusion of additional cases.

\section{Conflicts of Interest}

Chulsang Yoo and Jung Mo Ku declare that there are no conflicts of interest regarding the publication of this paper.

\section{Acknowledgments}

This research was supported by a grant from Water Management Research Program funded by Ministry of
Land, Infrastructure and Transport of Korean government (17AWMP-B079625-04).

\section{References}

[1] J. C. Alter, "Normal precipitation in UTAH," Monthly Weather Review, vol. 47, no. 9, pp. 633-636, 1919.

[2] C.-S. Chen, W.-C. Chen, Y.-L. Chen, P.-L. Lin, and H.-C. Lai, "Investigation of orographic effects on two heavy rainfall events over southwestern Taiwan during the Mei-yu season," Atmospheric Research, vol. 73, no. 1-2, pp. 101-130, 2005.

[3] A. J. Henry, "Increase of precipitation with altitude," Monthly Weather Review, vol. 47, pp. 33-41, 1919.

[4] P. J. Neiman, F. M. Ralph, A. B. White, D. E. Kingsmill, and P. O. G. Persson, "The statistical relationship between upslope flow and rainfall in California's coastal mountains: observations during CALJET," Monthly Weather Review, vol. 130, no. 6, pp. 1468-1492, 2002.

[5] R. B. Smith and I. Barstad, "A linear theory of orographic precipitation," Journal of the Atmospheric Sciences, vol. 61, no. 12, pp. 1377-1391, 2004.

[6] C.-K. Yu and L.-W. Cheng, "Radar observations of intense orographic precipitation associated with typhoon Xangsane (2000)," Monthly Weather Review, vol. 136, no. 2, pp. 497-521, 2008.

[7] J. M. Ku, Y. Ro, and C. Yoo, "Spatial variation of $Z-R$ relationship the Hallasan Mountain, Korea during the Typhoon Nakri in 2014," in Proceedings of the 37th Conference on Radar Meteorology, American Meteorological Society, Norman, Okla, USA, 2015.

[8] Jeju Regional Office Meteorology, Regional Climate Change Report (Jeju Island), Jeju Regional Office Meteorology, 2011.

[9] M. Um, W. Cho, and H. Rim, "Rainfall adjustment on duration and topographic elevation," Journal of Korea Water Resources Association, vol. 40, no. 7, pp. 511-521, 2007.

[10] G. Choi, "Spatial patterns of seasonal extreme precipitation events in Mt. Halla," KU Climate Research Institute, vol. 8, no. 4, pp. 267-280, 2013.

[11] Korea Meteorological Administration, 40 Years History of Weather Radar in Korea, Korea Meteorological Administration, 2012.

[12] J. Lee and C. Ryu, Radar Meteorology, Sigma press, 2009.

[13] D. M. A. Jones, Research Report: Rainfall Drop-Size Distribution and Radar Reflectivity, Illinois State Water Survey Meteorology Laboratory, 1956.

[14] D. C. Blanchard, "Raindrop size-distribution in hawaiian rains," Journal of Meteorology, vol. 10, no. 6, pp. 457-473, 1953.

[15] W. L. Woodley, A. R. Olsen, A. Herndon, and V. Wiggert, "Comparison of gage and radar methods of convective rain 
measurement," Journal of Applied Meteorology, vol. 14, no. 5, pp. 909-928, 1975.

[16] J. S. Marshall and W. M. K. Palmer, "The distribution of raindrops with size," Journal of Atmospheric Sciences, vol. 5, no. 4, pp. 165-166, 1948.

[17] Analysis Report: Typhoons Affecting the Korean Peninsula, National Typhoon Center, 2015.

[18] National Geographic Information Institute, The Geography of Korea-Jeju Special Self-Governing Province, National Geographic Information Institute, 2013.

[19] J. S. Marshall, R. C. Langille, and W. M. K. Palmer, "Measurement of rainfall by radar," Journal of Meteorology, vol. 4, no. 6, pp. 186-192, 1947.

[20] E. Aguado and J. E. Burt, Understanding Weather and Climate, Pearson, 4th edition, 2005.

[21] H.-J. Kim, K.-O. Lee, S.-A. Jung, D.-I. Lee, and H. Uyeda, "DSD characteristic of stratiform rainfall system passing on the western slope of Mt.Halla in Jeju Island during intensive observation period," in Proceedings of the Autumn Meeting of KMS, pp. 853-854, 2014.

[22] R. A. Houze Jr., "Orographic effects on precipitating clouds," Reviews of Geophysics, vol. 50, no. 1, Article ID RG1001, 2012.

[23] R. E. Passarelli Jr. and B. Hannah, "The orographic modulation of pre-warm-front precipitation in southern New England," Monthly Weather Review, vol. 111, no. 5, pp. 1062-1070, 1983.

[24] K. H. Choi, K. Y. Han, K. E. Kim, and C. H. Lee, "Development of a flood runoff and inundation analysis system associated with 2 -d rainfall data generated using radar i. quality control and cappi composite calculation," Journal of Korea Water Resources Association, vol. 39, no. 4, pp. 321-334, 2006.

[25] National Institute of Meteorological Research, Development of Very Short-Range Prediction System for Severe Weather, National Institute of Meteorological Research, 2008. 

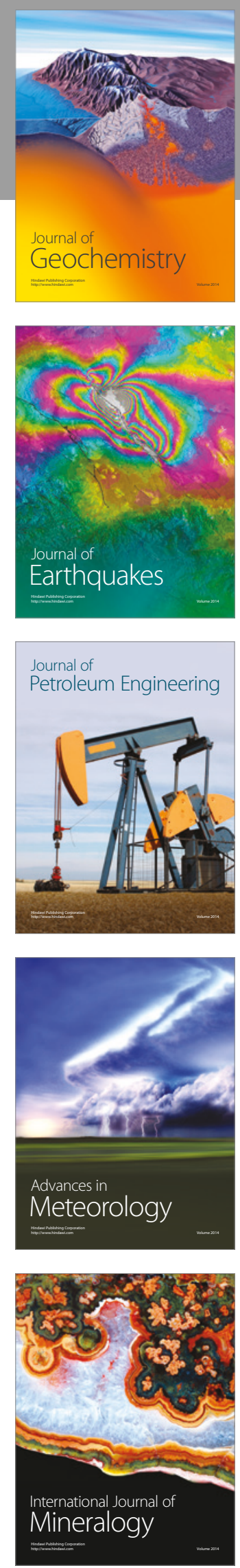
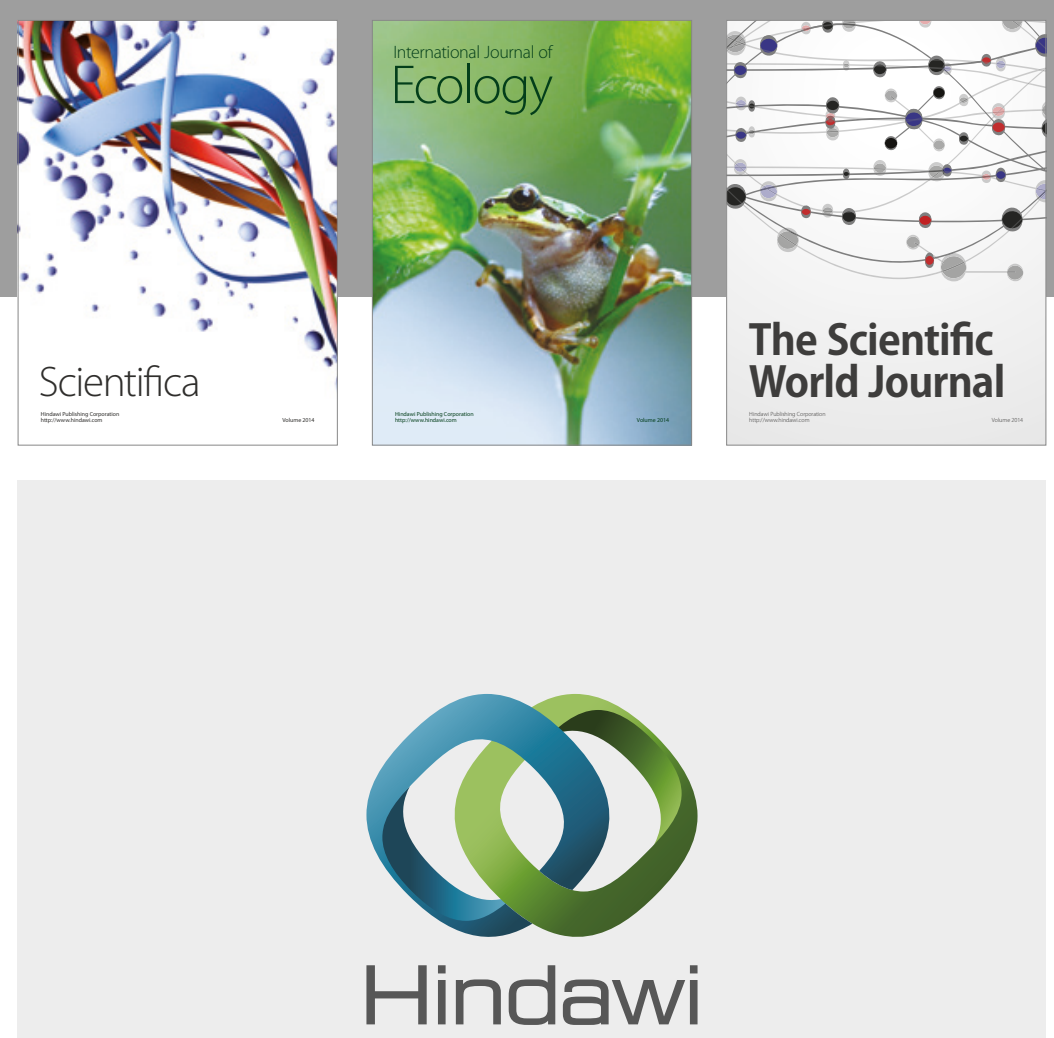

Submit your manuscripts at

https://www.hindawi.com
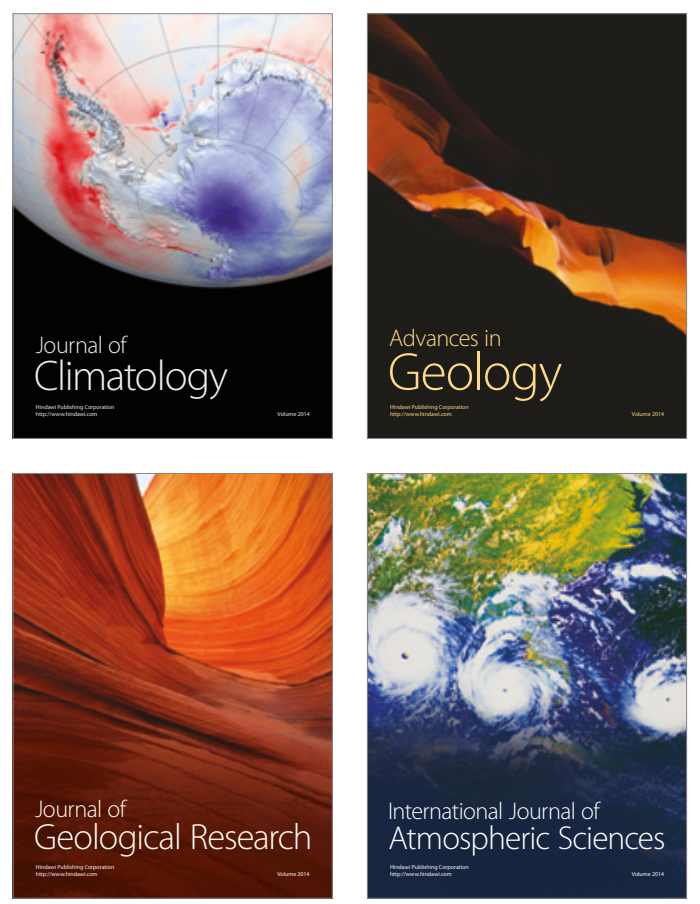

The Scientific

World Journal
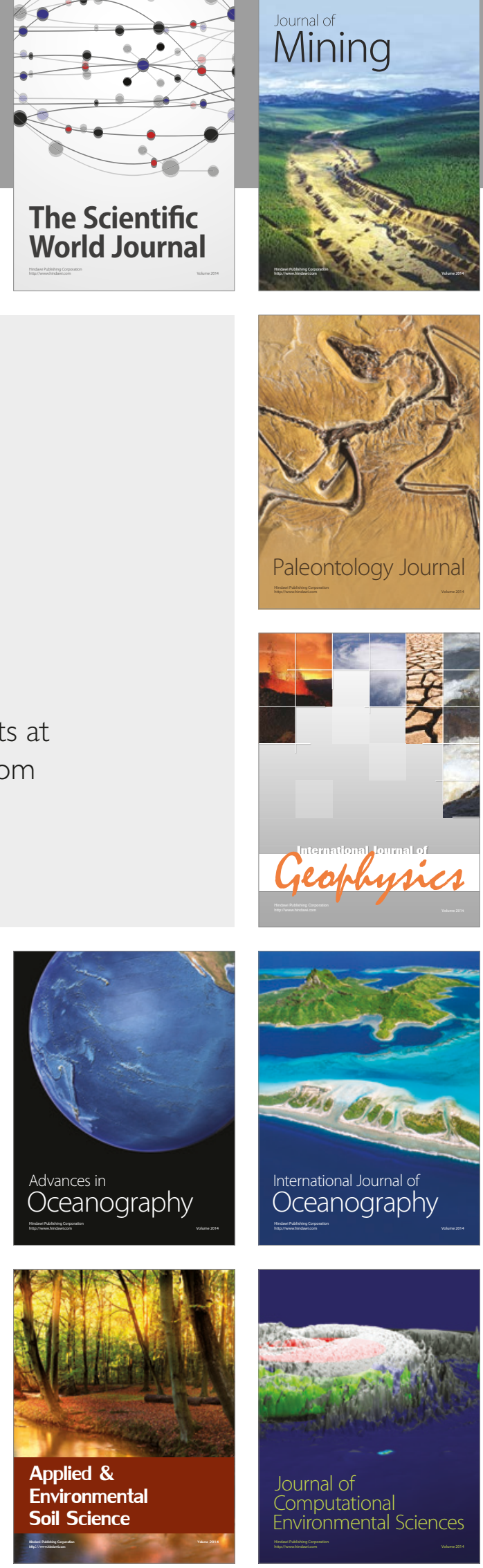